\title{
PERBEDAAN KECUKUPAN ASI ANTARA AKSEPTOR KB SUNTIK KOMBINASI DENGAN KB SUNTIK PROGESTIN PADA IBU MENYUSUI 0-6 BULAN DI WILAYAH KERJA PUSKESMAS SAMBIREJO SRAGEN
}

\author{
Chelia Ercy Adnara, Dwi Retna Prihati, Henik Istikhomah \\ Poltekkes Kemenkes Surakarta Jurusan Kebidanan \\ Diterima : 13 Januari 2019, Disetujui : 9 Februari 2019
}

\begin{abstract}
Background: Nursing mothers who do not want to get pregnant anymore need safe contraception, do not interfere with the breastfeeding process and do not affect breast milk production. Injection contraception is divided into two, namely combined injection family planning and progestin injection family planning. Combined injection family planning contains the hormone estrogen which can reduce the amount of breast milk production, while injectable progestin family planning contains the hormone prolactin which can stimulate the production of breast milk glands. One of the factors that influence the adequacy of breast milk is the use of contraception. Method: Type of observational research with cross sectional design. The sample in this study were all breastfeeding mothers who used injection contraception in the work area of Sambirejo Health Center Sragen in September to November 2018 as many as 62 people. Total sampling technique, chi square analysis. Results: Characteristics of acceptor age, namely 20-35 years as many as 52 people (83.9\%) education namely high school as many as 30 people (48.4\%), occupations namely housewives as many as 46 people (74.2\%) and parity is primipara 33 people (53.2\%). The adequacy of breastfeeding in breastfeeding mothers who use combined injection contraception is mostly 16 people (25.8\%) and not enough as many as 12 people (19.4\%). The adequacy of breastfeeding in breastfeeding mothers who use the progestin injection contarction is mostly 32 people (51.6\%) and not enough as many as 2 people (3.2\%). The chi square test results $p=0.001$ ( $p<0.05)$. Conclusion: There is a difference in the adequacy of breastfeeding between family planning injection acceptors combined with Progestin injections in breastfeeding mothers 0-6 months in the working area of Sambirejo Sragen health center.
\end{abstract}

Keywords: Combination And Progestin Contraception, Adequacy Of Breastfeeding

\section{PENDAHULUAN}

Kontrasepsi hormonal terutama kontrasepsi suntikan merupakan kontrasepsi yang paling diminati akseptor $\mathrm{KB}$ yang paling aman, praktis, tidak perlu mengingat-ingat setiap hari (BKKBN, 2013). Kontrasepsi suntikan yang dapat diberikan kepada ibu menyusui adalah suntikan yang berbasis progestin.
Kontrasepsi suntikan ini dapat diberikan pada ibu menyusui segera setelah masa pasca persalinan. Kontrasepsi suntikan tidak mempengaruhi produksi ASI (berbasis progestin) (Hariyanti, 2017). Fungsi hormon Progestin adalah mempengaruhi pertumbuhan dan ukuran alveoli (Prawirohardjo, 2010). Hormon ini tidak begitu mempengaruhi laktasi, 
kemungkinan dapat memperbaiki kuantitas produksi ASI (memperbanyak produksi ASI) dan tidak mempengaruhi komposisi ASI (Hanafi, 2010). Sedangan Pemberian progestin (DMPA) juga akan berdampak pada produksi ASI jika diberikan pada awal post partum) (Barens, 2015). Sedangkan hormon esterogen yang dapat menurunkan jumlah produksi ASI. ASI merupakan sumber nutrisi terbaik bagi bayi, karena sifatnya alami dan komposisi lengkap serta sesuai bagi bayi. ASI sangat penting bagi bayi karena ASI makanan utama bagi bayi. ASI dikatakan cukup bagi bayi jika terdapat ciri-ciri antara antara lain ASI merembes keluar puting susu ibu, bayi menyusui selama (>10 menit) setiap kali menyusu, setelah menyusui bayi tidak rewel dan bayi buang air kecil sering (> 6 kali) dalam sehari, ibu mendengar suara menelan ketika bayi menelan ASI, ibu merasa geli setiap kali bayi menyusu, anak menyusui lebih dari enam kali dalam sehari, bayi buang air besar lebih dari tiga kali dalam sehari (Astutik, 2017). Faktor yang mempengaruhi kecukupan ASI yaitu faktor ibu dan faktor bayi. Faktor ibu meliputi faktor makanan ibu, riwayat penyakit, faktor psikologis, konsumsi alkohol, cara menyusui yang tepat dan penggunaan kontrasepsi. Faktor bayi meliputi faktor isapan bayi, faktor penyusuan, berat badan lahir dan rawat gabung (Indriyani, Asmuji dan Wahyuni, 2016). Penggunaan kontrasepsi yang tidak tepat dapat mempengaruhi ASI (Ambarwati, 2008). Hal ini dibuktikan dengan fenomena yang ada di lapangan cukup banyak ibu menyusui yang menggunakan kontrasepsi suntik ASI tetap lancar. Hasil wawancara di Puskesmas Sambirejo pada 10 ibu menyusui sebanyak 6 orang adalah akseptor KB suntik 1 bulan dan 4 orang akseptor suntik 3 bulan, didapatkan 6 orang mengatakan pada saat menyusui bayi terkadang rewel setelah menyusu dan bayi menyusu < 10 menit setiap kali menetek. Hal inilah yang mendorong peneliti melakukan penelitian tentang "Perbedaan Kecukupan ASI antara Akseptor KB Suntik Kombinasi dengan KB Suntik Progestin pada Ibu Menyusui 0-6 Bulan di Wilayah Kerja Puskesmas Sambirejo Sragen".

Penelitian ini bertujuan mengetahui Perbedaan Kecukupan ASI antara Akseptor KB Suntik Kombinasi dengan KB Suntik Progestin pada Ibu Menyusui 0-6 Bulan di Wilayah Kerja Puskesmas Sambirejo Sragen.

\section{METODE PENELITIAN}

Jenis penelitian observasional dengan rancangan cross sectional. yaitu penelian untuk mempelajari dinamika kontrasepsi suntik terhadap pengaruh pengeluaran ASI sebagai efek, dengan cara mengumpulkan data sekaligus pada saat penelitian. Subyek hanya diobservasi sekali saja dan pengukurannya dilakukan terhadap variabel subyek pada saat penelitian.

Penelitian ini dilakukan di wilayah kerja Puskesmas Sambirejo mulai bulan September 2018 sampai dengan Januari 2019. Populasi pada penelitian ini adalah semua ibu menyusui yang menggunakan kontrasepsi suntik di wilayah kerja Puskesmas Sambirejo Sragen pada bulan September sampai November tahun 2018 sebanyak 62 orang. Pada saat seleksi sampel semua responden bersedia dan tidak ada yang mengalami mastitis dan bendungan payudara, sehingga sampel sama dengan populasi (total sampling) sejumlah 62 orang. 
Pada penelitian ini, peneliti menggunakan checklist kecukupan ASI dari indikator bayi (6 indikator) dan indikator ibu (10 indikator). Pengumpulan data dilakukan oleh peneliti dan enumerator pada tanggal 1 September sampai 31 November 2018.

Analisa data pada penelitian ini dengan Chi square menggunakan uji statistik komputer.

\section{HASIL PENELITIAN}

Tabel 1. Distribusi Frekuensi Karakteristik di wilayah Puskesmas Sambirejo Sragen

\begin{tabular}{lll}
\hline \multicolumn{1}{c}{ Karakteristik } & F & \% \\
\hline Umur & & \\
$<20$ tahun & 0 & 83,9 \\
20-35 tahun & 52 & 16,1 \\
$>35$ tahun & 10 & \\
\hline Pendidikan & & \\
SD & 8 & 12,9 \\
SMP & 24 & 38,7 \\
SMA & 30 & 48,4 \\
PT & 0 & 0 \\
\hline Pekerjaan & & \\
IRT & 46 & 74,2 \\
Swasta & 15 & 24,2 \\
Petani & 1 & 0 \\
& &
\end{tabular}

\begin{tabular}{lll}
\hline Paritas & 33 & 53,2 \\
G1 & 27 & 43,5 \\
G2 & 0 & 0 \\
G3 & 2 & 3,2 \\
G4 & 62 & 100 \\
\hline Jumlah & \\
\hline
\end{tabular}

Berdasarkan tabel 1 diketahui

bahwa sebanyak 52 orang $(83,9 \%)$ berumur 20-35 tahun, pendidikan responden adalah SMA sebanyak 30 responden $(48,4 \%)$. Pekerjaan responden sebagian besar adalah ibu rumah tangga sebanyak 46 orang $(74,2 \%)$ dan paritas responden sebagian besar adalah primipara sebanyak 33 orang $(53,2 \%)$.
Tabel 2 . Distribusi Frekuensi Kontrasepsi Suntik di Wilayah Kerja Puskesmas Sambirejo Sragen

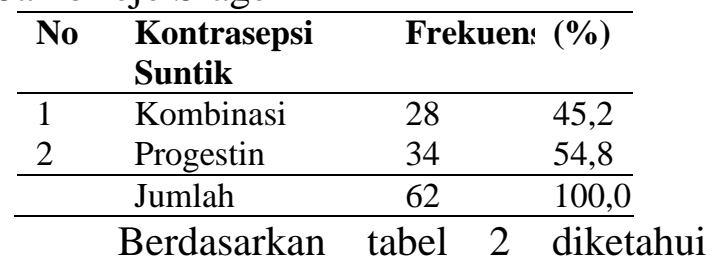
responden yang menggunakan $\mathrm{KB}$ suntik progestin bulan sebanyak 34 orang $(54,8 \%)$ dan $\mathrm{KB}$ suntik kombinasi sebanyak 28 orang $(45,2 \%)$.

Tabel 3. Distribusi Frekuensi Kecukupan ASI

\begin{tabular}{llll}
\hline $\begin{array}{l}\text { No } \\
\end{array}$ & $\begin{array}{l}\text { Kecukupan } \\
\text { ASI }\end{array}$ & Frekuensi & \% \\
\hline 1 & Cukup & 38 & 61,3 \\
2 & Tidak Cukup & 24 & 38,7 \\
\hline & Jumlah & 62 & 100,0 \\
\hline & Berdasarkan & dabel & diketal
\end{tabular}

Berdasarkan tabel 3 diketahui responden sebanyak 38 orang $(61,3 \%)$ cukup dan tidak cukup sebanyak 24 orang $(38,7 \%)$.

1. Analisa Bivariat

Data yang diperoleh dalam penelitian merupakan data nominal $><$ ordinal sehingga teknis analisis statistik yang digunakan adalah chi square.

Tabel 4. Perbedaan Kecukupan ASI antara Akseptor KB Suntik Kombinasi dengan KB Suntik Progestin pada Ibu Menyusui 0-6 Bulan di Wilayah Kerja Puskesmas Sambirejo Sragen

\begin{tabular}{|c|c|c|c|c|c|c|c|}
\hline \multirow{3}{*}{$\begin{array}{c}\text { Kontrasepsi } \\
\text { Suntik }\end{array}$} & \multicolumn{5}{|c|}{ Kecukupan ASI } & Total & \multirow{3}{*}{$p$} \\
\hline & \multicolumn{2}{|c|}{ Cukup } & \multicolumn{2}{|c|}{$\begin{array}{l}\text { Tidak } \\
\text { Cukup }\end{array}$} & \multirow[t]{2}{*}{$\mathbf{F}$} & \multirow[t]{2}{*}{$\%$} & \\
\hline & $\mathbf{F}$ & $\%$ & & $\%$ & & & \\
\hline Kombinasi & 16 & 25,8 & 12 & 19,4 & 28 & 45,2 & $\overline{0,001}$ \\
\hline Progestin & 32 & 51,6 & 2 & 3,2 & 34 & 54,8 & \\
\hline Jumlah & 28 & 45,2 & 34 & 21,9 & 62 & 100 & \\
\hline
\end{tabular}

Berdasarkan tabel 4 diketahui bahwa sebanyak 62 orang menggunakan kontrasepsi suntik. Responden yang menggunakan kontrasepsi suntik 
kombinasi sebanyak 28 orang dengan kecukupan ASI termasuk kategori cukup sebanyak 16 orang $(25,8 \%)$ dan tidak cukup sebanyak 12 orang $(19,4 \%)$, sedangkan responden yang menggunakan kontrasepsi suntik progestin sebanyak 34 orang dengan kecukupan ASI termasuk kategori cukup sebanyak 32 orang $(51,6 \%)$ dan tidak cukup sebanyak 2 orang $(3,2 \%)$.

\section{PEMBAHASAN}

Berdasarkan hasil uji statistik dengan Chi Square didapatkan nilai $p=$ $0,001 \quad(\alpha<0,05)$, jadi ada perbedaan kecukupan ASI antara akseptor KB suntik kombinasi dengan $\mathrm{KB}$ suntik progestin pada ibu menyusui 0-6 bulan di wilayah kerja Puskesmas Sambirejo Sragen. Hasil ini menunjukkan bahwa Ha diterima dan Ho ditolak sehingga ada hubungan yang signifikan antara kontrasepsi suntik dengan kecukupan ASI, $p=0,001$ $(\alpha<0,05)$.

Hasil ini menunjukkan bahwa di dalam ASI terdapat hormon prolaktin dihasilkan oleh kelenjar hipofisa bagian depan otak. Prolaktin merangsang kelenjar produksi ASI. Salah satu keuntungan KB suntik progestin adalah tidak mengurangi produksi ASI. Akan tetapi jika dilihat kembali mekanisme kerja hormon estrogen dan progesteron juga mempunyai efek khusus untuk menghambat sekresi susu sebenarnya. Di pihak lain hormon prolaktin mempunyai efek yang tetap berlawanan, meningkatkan poduksi ASI jika diberikan awal postpartum (Barens, 2015).

Sedangkan KB suntik kombinasi terdapat hormon estrogen, kandungan estrogen atau estradiol spionat dapat menurunkan jumlah produksi ASI, sehingga menghambat kelancaran ASI selama laktasi (Hanafi H, 2010). Bagi Ibu yang dalam masa menyusui, tidak dianjurkan menggunakan kontrasepsi suntikan yang mengandung estrogen karena hal ini dapat menurunkan jumlah produksi ASI, sehingga dapat menghambat kelancaran pengeluaran ASI selama masa laktasi. Kadar estrogen yang tinggi pada kontrasepsi dapat menekan FSH, sehingga merangsang lobus anterior hipofise untuk mengeluarkan luteinising hormon. Produksi luteinising hormon ini dibawah pengaruh releasing hormon yang disalurkan dan hipotalamus ke hipofisis. Adanya sekresi luteinising hormon, maka dapat menyebabkan hipotalamus untuk melepas faktor penghambat prolaktin (PIF) yang dianggap sebagai dopamin. Dopamin ini dapat menurunkan sekresi prolaktin sampai sepuluh kali lipat. Bila sekresi prolaktin dihambat, maka sel-sel alveoli pada payudara tidak akan memproduksi air susu. Dengan tidak adanya produksi air susu, maka pengeluaran ASI juga terhambat (Verrals, 2010).

Berdasarkan penelitian Sari, Prihandiwati dan Suswati (2016) tentang Pengaruh Pemakaian Kontrasepsi Suntik 1 Bulan dan 3 Bulan Terhadap Produksi ASI pada Ibu Menyusui di Puskesmas Perawatan Kelua Kabupaten Tabalong dengan hasil ada pengaruh pemakaian kontrasepsi suntik 1 bulan dan 3 bulan terhadap produksi ASI pada ibu menyusui di Puskesmas Perawatan Kelua Kabupaten Tabolong. Dengan rata-rata volume ASI ibu menyusui yang menggunakan kontrasepsi suntik 1 bulan adalah $120 \mathrm{ml}$ dan yang menggunakan kontrasepsi suntik 3 bulan adalah $167,8 \mathrm{ml}$. 


\section{KESIMPULAN DAN SARAN}

Berdasarkan hasil penelitian dapat disimpulkan bahwa Ada Perbedaan Kecukupan ASI antara Akseptor KB Suntik Kombinasi dengan KB Suntik Progestin yang signifikan pada Ibu Menyusui 0-6 Bulan di Wilayah Kerja Puskesmas Sambirejo Sragen. Selain itu, diharapkan kepada bidan agar mampu meningkatkan kualitas pelayanan KB terutama pada saat konseling KB pada ibu menyusui guna ibu tidak salah memilih alat kontraspsi, sehinggga tidak mempengaruhi produksi ASI nya serta diharapkan bagi peneliti selanjutnya hendaknya melakukan penelitian tentang faktor-faktor yang mempengaruhi kecukupan ASI dengan lebih terperinci untuk melihat faktor apa yang paling berpengaruh terhadap kecukupan ASI pada bayi usia 0-6 bulan.

\section{DAFTAR RUJUKAN}

Ambarwati, E, \& Wulandari, D. 2008. Asuhan Kebidanan Nifas. Yogyakarta: Cendekia Press.

Ambarwati, E, \& Wulandari, D. 2010. Asuhan Kebidanan Nifas. Yogyakarta: Cendekia Press.

Anna Glasier, Ailsa Gebbie. 2006. Keluarga Berencana \& Kesehatan Reproduksi. Jakarta : EGC.

Arikunto S. 2010. Prosedur Penelitian Suatu Pendekatan Praktik. Jakarta: Rineka Cipta.

Astutik, R.Y. 2017. Payudara dan Laktasi. Jakarta: Salemba Medika.

BKKBN. 2013. Pemantauan Pasangan Usia Subur Melalui Mini Survei Indonesia. Jakarta: BKKBN.

Dewi, Vivian Nanny Lia; Sunarsih, Tri. 2011. Asuhan Kebidanan Ibu Nifas. Jakarta : Salemba Medika.
Edmond K M, Bard E C, dan Kirkwood B A. 2006. Delayed Breastfeeding Initiation Increase Risk of Neonatal Mortality. Pediatrics. Vol 117(3)e380e386

Faiqah. 2014. Perbedaan Berat Badan dan Tekanan Darah Systole Ibu Sebelum dan Sesudah Menggunakan Kontrasepsi Suntik 3 Bulan/DMPA. Skripsi.

Firdaus, Y. 2015. Konsep Pemilihan Lokasi dan Efektivitas Pasar.http://eprints.uns.ac.id/22622 13/I0611026_bab2.pdf. Diakses pada 16 Agustus 2018.

Hanafi, 2010. Keluarga Berencana dan Kontrasepsi . Jakarta : Sinar Harapan.

Hartanto. 2014. Keluarga Berencana dan Kontrasepsi . Jakarta : Sinar Harapan.

Hariyanti, 2017. Perbedaan Produksi ASI pada Akseptor KB Suntik Kombinasi dan Progestin di BPS Anugerah Kabupaten Malang. Skripsi

Hardianti, dkk. 2010. Karakteristik peserta KB drop out Kecamatan Wawotobi Kabupaten Konawe Provinsi Sulawesi Tenggara. Fakultas Kesehatan Masyarakat Universitas Hasanuddin: Makassar. Online. diakses 13 November 2018.

Indriyani, Diyan \& Asmuji. 2016. Buku Ajar Keperawatan Maternitas. Yogyakarta: Ar-Ruzz Media.

Kamus Besar Bahasa Indonesia (KBBI) Luar Jaringan (offline), Pusat Bahasa.

Montolalu. 2009. Bermain dan Permainan Anak. Jakarta: Universitas Terbuka. 
Notoatmodjo, S. 2010. Metodologi Penelitian Kesehatan. Jakarta : Rineka cipta.

Notoatmodjo, S. 2014. Metodologi Penelitian Kesehatan. Jakarta : Rineka cipta.

Prawirohardjo, S. 2000. Ilmu Kebidanan. Jakarta : Yayasan Bina Pustaka.

Purwaningsih dan Wati. 2011. Pengaruh Kontrasepsi Suntik terhadap Pengeluaran ASI di BPS Tri Paryati Kemalang Kabupaten Klaten. Skripsi.

Proverawati. 2009. ASI dan Menyusui. Yogyakarta : Nuha Medika.

Roesli, Utami. 2009. Mengenal ASI Eksklusif. Jakarta: Trubus Agriwidya.

Saifuddin. 2008. Ilmu Kebidanan, edisi 4. Jakarta: Bina Pustaka.

Saleha, S. 2009. Asuhan Kebidanan pada Masa Nifas. Jakarta: Salemba Medika.

Sanger, dkk. 2008. Pengaruh suntikan depo medroxyprogesteron asetat terhadap profil lipid.

Santoso, Singgih, 2011. "Statistik Non Parametrik Konsep dan Aplikasi dengan. SPSS". Jakarta: Penerbit PT.

Soekanto, Soerjono. 2012.Sosiologi Suatu Pengantar. Jakarta: Rajawali Pers.

Siswosudarmo, R. 2010. Obstetri fisiologi. Jogjakarta : Pustaka Cendikia.

Sugiyono. 2012. Statistik Untuk Penelitian. Bandung : Alfabeta.
Suherni, 2009. Perawatan Masa Nifas. Yogyakarta: Fitramaya.

Sulistyawati. 2011. Asuhan kebidanan pada masa kehamilan. Jakarta : Salemba Medika.

Sulistyawati, 2009. Tumbang,status gizi,dan imunisasi dasar. Yogyakarta : Nuha Medika.

Suparwati. 2016. Hubungan Kecukupan ASI dengan Stress Psikososial pada Ibu Nifas di BPM Suparwati Trucuk Klaten. Skripsi. Poltekkes Surakarta

Suratun, Lusianah. 2008. Asuhan Keperawatan Klien Dengan Gangguan Sistem Gastrointestinal. Jakarta: Trans Info Media

Welford, 2008. Menyusui Bayi Anda. Jakarta: Penerbit PT.Dian Rakyat.

\section{WWW.ASK.COM}

ttps://knowlection.wordpress.com/ 2010/10/16/search-engine-askcom/. Diakses pada 8 September 2018.

Yahya. 2007. Cairan Ajaib Air Susu Ibu. Jakarta.

Zuhana N, Nur Izzah dan Aida R. 2011. Faktor-Faktor Mempengaruhi Perilaku Pemberian ASI Eksklusif pada Ibu Menyusui di Kecamatan Wonopringo Kabupaten Pekalongan. Jurnal Ilmiah Kesehatan. 1(1). 